\section{SME}

ESTD 2005

\title{
DEVELOPMENT AND TESTING OF EVACUATED BOX SOLAR COLLECTOR
}

\author{
* Daksh R Tandel and Ashish O Jain
}

Department of Mechanical Engineering, GDEC, Navsari, Gujarat- 396406, India

https://doi.org/10.37255/jme.v15i1pp012-014

\begin{abstract}
By looking at the scarcity of fossil fuel and its polluting nature, there is a need to find out, other sources of energy for different application. For solar cooking and steam generation application, different solar collectors are there but its use is limited and it is not commercially accepted so it becomes necessary to find some alternate way of heating in solar cooker. So, in this work one solar collector is developed and tested for maximum temperature achieved and finally its feasibility for solar cooker application is checked.
\end{abstract}

Keywords: Acrylic cover, Vacuum Gauge, Vacuum Pump and Black colored metallic plate.

\section{Introduction}

Flat plate box cooker, Box type solar oven, parabolic disc concentrator type solar cooker, Schaffer cooker, Panel cooker and Hybrid cooker are the types of solar cooker.

Some of the disadvantages of solar cooker are that 1) It takes more time for cooking 2) It has to be operated at outside of cooking area 3) Cooking is only possible during day time.

In water heating application, use of evacuated tube water heater is continuously increasing in this regard if same concept is applied to cooking application its uses may increase so one solar collector with evacuated box is developed and tested.

\section{Literature Survey}

Balzar et al. [1] tested solar cooker using vacuum tube integrated with heat pipe and concluded that $250^{\circ} \mathrm{C}$ temperature can be obtained by using water as working medium.

Rakesh kumar et al. [2] developed and tested community type solar cooker based on evacuated tube solar collector. The developed design had separate parts for energy collection and cooking unit. Both were connected through heat exchanger.

Sharma et al. [3] developed solar cooker based on evacuated tube and PCM material as heat storage medium. Commercial grade erythritol was used as a latent heat storage material. Noon and evening cooking experiments were conducted with different loads and loading times.

*Corresponding Author - E- mail: drt.med@gdec.in
Suhail Zaki Farooqui [4] developed vacuum tube based solar cooker by use of primary and secondary reflector.Solar tracker mechanism was provided to the primary reflector through common driver.

Abd-Elhady et al. [5] developed and tested evacuated tube based solar cooker and studied the influence of inserting metallic wires or nanographene particles on the thermal performance of the cooker

\section{Objective and Scope}

Objective of this project is to develop a lowcost solar heater that can achieve high temperature so it can be utilized in application like solar cooking and solar steam generation.

\section{Parameter Selection}

In this project one mild steel metal plate which is of dimension $20 \mathrm{~cm} \mathrm{X} 20 \mathrm{~cm}$ is taken (Figure 1). Metallic plate is colored with black colour on one of the sides.

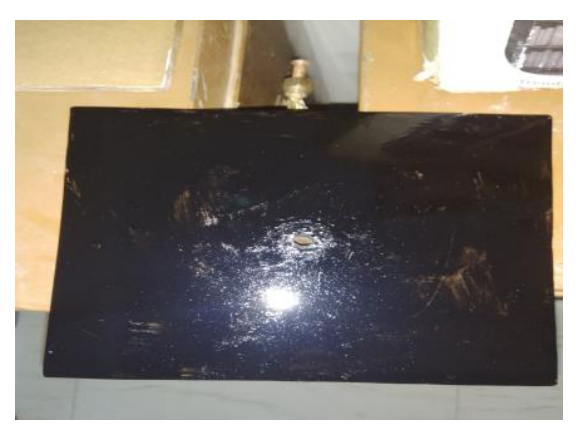

Fig. 1 Mild steel plate 
In metallic plate, one tube is connected and at the end of this tube one valve and pressure gauge is connected as shown in Figure 2.

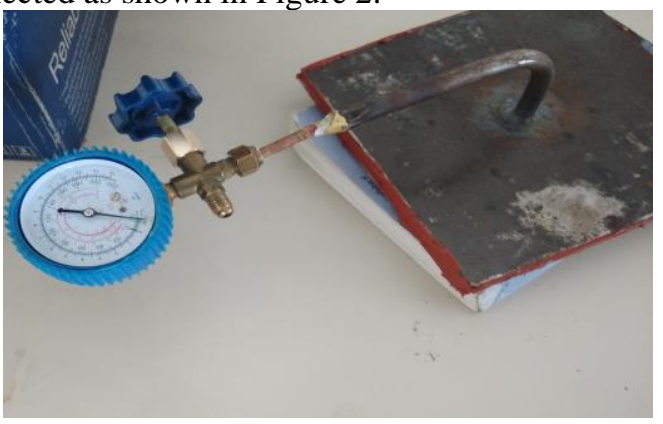

Fig. 2 Gauge and valve connected with plate

Acrylic is selected as a transparent device which has dimension similar to metallic plate. Red silicon rubber is used between acrylic and metallic plate to create leak proof space. Glass wool is selected as insulation material. Vacuum pump is used to remove air from closed space. To measure temperature PT 100 sensor with indicator is selected. All the components are connected as shown in Figure 3.

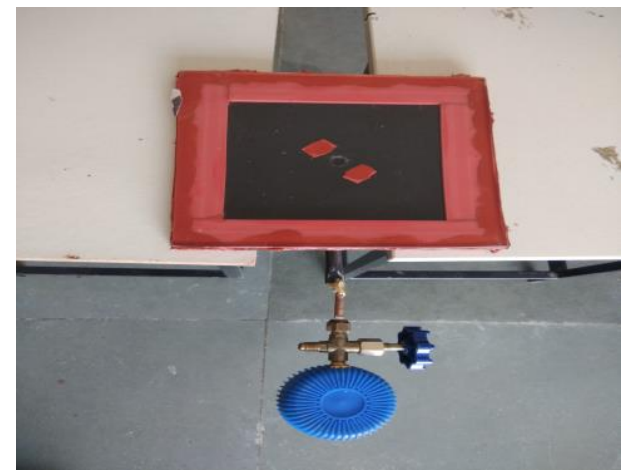

Fig.3 Assemble unit

\section{Development}

Initially one metallic plate of $20 \mathrm{~cm} \mathrm{x} 20 \mathrm{~cm}$ is cut from sheet then at center one hole is drilled in which one tube of mild steel is welded and at the end of mild steel tube one copper tube is welded. Copper tube is flared so that valve can be easily fitted. Then with copper tube one valve with compound gauge is connected. Valve is selected in such a way that vacuum pump with the help of flexible tube can be connected.

On metallic plate silicon rubber spacer is kept. On silicon rubber spacer, acrylic sheet of $8 \mathrm{~mm}$ thickness is fitted. Care regarding leak proof joint is taken.
On bottom side of plate, glass wool insulation is provided so bottom heat loss can be minimised.PT 100 sensors are pasted with metal plate and sensor is connected with temperature indicator. (Figure 4)

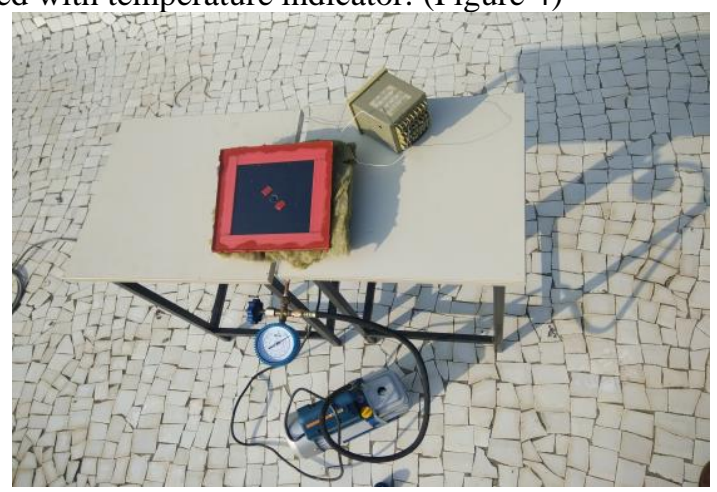

Fig.4 Experimental set up

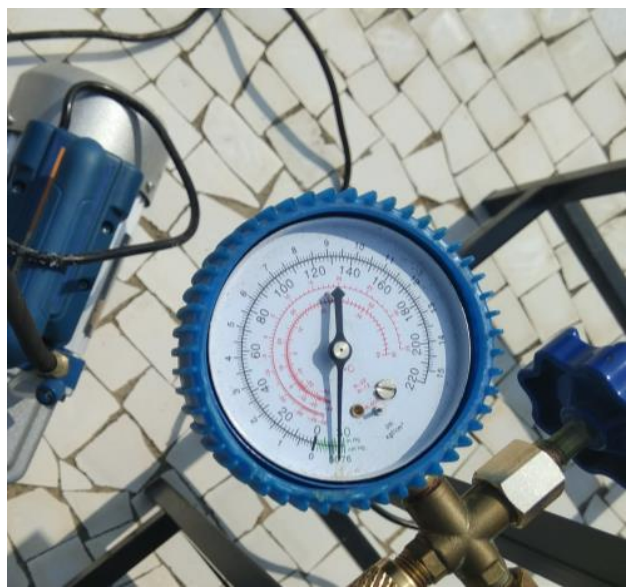

Fig.5 Vacuum reading

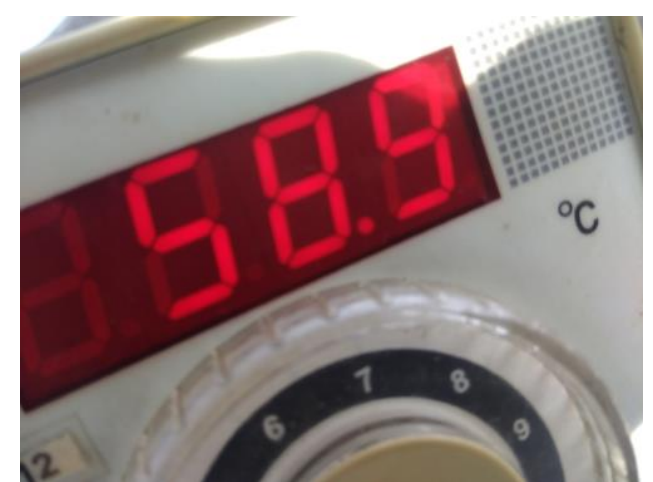

Fig. 6 Temperature Reading

Figure 5 and Figure 6 shows the setup for Vacuum and Temperature readings. 
Journal of Manufacturing Engineering, June 2020, Vol. 15, Issue. 1, pp 012-014

Table 1 Variation of temperature with time

\begin{tabular}{cc}
\hline Time & Temperature IN ${ }^{\mathbf{0}} \mathbf{C}$ \\
\hline $9: 20 \mathrm{am}$ & 34.7 \\
$9: 40 \mathrm{am}$ & 40.1 \\
$10: 00 \mathrm{am}$ & 46.6 \\
$11: 00 \mathrm{am}$ & 55.0 \\
$12: 00 \mathrm{noon}$ & 59.4 \\
$01: 00 \mathrm{pm}$ & 61.1 \\
$02: 00 \mathrm{pm}$ & 58.9 \\
\hline
\end{tabular}

\section{Conclusion}

From experiment it can be concluded that there is a rise in temperature with time but with very slow rate and maximum temperature reached is $61.1^{\circ} \mathrm{C}$ (Table 1). Reason for slow heating are 1) Surface area exposed to sun is very less. 2) Not only plate but insulation also should be provided to metallic tube and valve so heat loss from them can be reduced.3) Performance also can be improved if silicon rubber covered area is reduced.

Surely if all problems will be minimized then performance of low cost evacuated box solar collector can be increased. One of the biggest advantages of this collector is that it can be developed without use of costly equipment and with very easy technic.

\section{References}

1. Balzar A, Stumpf P, Eckhoff S, Ackermann H and Grupp $M$ (1996), "a solar cooker using vacuum-tube collectors with integrated heat pipes", Solar Energy Vol. $58: 1-3,63-68$.

2. Rakesh kumar, Adhikari R S, Garg H P and Ashvini kumar (2001), "Thermal performance of a solar pressure cooker based on evacuated tube solar collector", Applied Thermal Engineering, vol. 21:1699-1706.

3. Sharma SD, Takeshi Iwata, Hiroaki Kitano and Kazunobu Sagara (2005), "Thermal performance of a solar cooker based on an evacuated tube solar collector with a PCM storage unit", Solar Energy, vol.78: 416-426.

4. Suhail Zaki Farooqui (2013), "A vacuum tube based improved solar cooker”, Sustainable Energy Technologies and Assessments, vol. 3: 33-39.

5. Abd-Elhady MS, Abd-Elkerim ANA, Seif A. Ahmed, Halim MA and Ah d Abu-Oqail (2019)," Study the thermal performance of solar cookers by using metallic wires and nanographene", Renwable energy. 